Revista

$A \circlearrowright O r$

das Ietras

\title{
Bolaño, o investigador da vida e dos versos pelas trilhas do valor e do medo
}

\author{
Bolaño, the investigator of life and verses by the trails of courage and fear
}

\author{
Edson Oliveira da Silva* \\ Universidade Estadual de Feira de Santana, \\ Feira de Santana, Bahia, Brasil
}

\begin{abstract}
Resumo: A leitura do romance Los detectives salvajes do escritor chileno Roberto Bolaño nos coloca diante de uma narrativa inquietante, pautada no jogo sinuoso entre ficção e realidade, de modo que as ambições e experiências do escritor, enquanto "homem vulgar" e intelectual se confundam, em diferentes circunstâncias, com as tramas vividas pela legião de personagens que povoam a ficção. Nesse sentido, para além de representar a história latino-americana, marcada pela explosão de vozes e conflitos entranhados, desde séculos atrás na genealogia deste espaço, onde o vazio e a errância se destacam muito mais do que os encontros e as convicções, esta narrativa nos apresenta um fluxo descontínuo de experiências e discursos, em que a literatura se apresenta como um caminho para compreender melhor os nossos instintos e mazelas. Sob esse ponto de vista, partindo da possibilidade de que alinhemos a produção literária de Bolaño a uma onda de fenômenos políticos e culturais, quase sempre ligados à ideia de deslocamento e fragmentação, que assinalam a contemporaneidade, este estudo se preocupa em reconhecer a figura do escritor como uma espécie de detetive incansável, que, tanto dentro quanto fora da ficção, se propõe a investigar a vida e a poesia, percorrendo os campos invisíveis do valor e do medo.
\end{abstract}

Palavras-chave: Roberto Bolaño. Investigador. Valor. Medo.

Abstract: The reading of the novel Los Detectives Salvajes of the Chilean writer Roberto Bolaño puts us before a disturbing narrative, based on the winding game between fiction and reality, so that the ambitions and experiences of the writer as "vulgar man" and intellectual are confused, in different Circumstances, with the plots lived by the legion of characters who populate fiction. In this sense, in addition to representing Latin American history, marked by the explosion of voices and conflicts entrenched for centuries in the genealogy of this space, where the emptiness and wandering stand out much more than encounters and convictions, this narrative presents us with a discontinuous flow of experiences and discourses, in which literature presents itself as a way to better understand our instincts and ills. From this perspective, starting from the possibility that we align the literary production of Bolaño to a wave of political and cultural phenomena, almost always linked to the idea of displacement and fragmentation, that mark contemporaneousness, this study is concerned with recognizing the figure of the writer as a kind of indefatigable detective who, both inside and outside of fiction, proposes to investigate life and poetry, through the unfeasible fields of courage and fear.

Keywords: Roberto Bolaño. Investigator. Courage. Fear.

* Doutor em Literatura e Cultura (UFBA), Professor Assistente da Universidade Estadual de Feira de Santana, Bahia, Brasil. Tem experiência na área de Letras, com ênfase em Literatura Contemporânea da América Latina. E-mail: edsonn.oliveira28@yahoo.com.br. 
É de nosso conhecimento que na tradição da literatura latino-americana, destacamse os nomes de alguns escritores, como por exemplo, Jorge Luis Borges e Gabriel García Márquez, em virtude do trabalho de comunicação entre a imaginação produzida por possíveis leitores e a ficção que constroem, como também em razão do diálogo estabelecido entre o texto literário e as suas próprias vidas, e as imagens públicas que passaram a representar. No caso específico de Roberto Bolaño, um detetive por excelência, um escritor profissional sempre envolvido em dificuldades financeiras que o obrigaram a converter-se em um assíduo participante de concursos literários, muitos deles sem maior expressão, um poeta marginal, um contestador da vida e das verdades prontas, decidimos destacar nesse momento a sua eminente preocupação em perseguir as pistas que pudessem explicar a sua existência enquanto sujeito e, de alguma forma, elucidar os enigmas ainda escondidos na terra selvagem de seus mundos ficcionais.

Bolaño era, de fato, um detetive. Talvez, um tipo raro, significativamente, distante da imagem caricata do investigador perspicaz, que, com lupa e luvas de couro que the cobriam milimetricamente as mãos, povoava a literatura policial durante o seu auge, no segundo quartel do século XX, na Europa e grande parte da América Latina (MASSI, 2011, p.25). É certo que não estamos diante de um tipo humano oriundo da mesma matéria que produziu Sherlock Holmes. Bolaño é um investigador desvelado, suas luvas não lhe protegem os dedos, e quase sempre sua ação não é justificada pela necessidade de desvendar mistérios, apontando eficazmente o autor de determinado crime, sob o pretexto de que se cumpra a lei. Em lugar disso, o seu interesse está em refazer o percurso do "marginal", reconhecer visceralmente a cena do crime, penetrando-a, compactando-a, reformando-a, atribuindo-lhe, por vezes, um tônus de vulgaridade capaz de remover o delito de seu lugar de sacrilégio irretocável, passível apenas de julgamento e condenação, conduzindo-o, pois, para um espaço marcado pela ideia do movimento, do transe, da busca, da peregrinação e não do sacrifício.

Se, a respeito de 2666 (2004), costuma-se dizer que é o romance em que Bolaño desenvolve brilhantemente o seu estilo narrativo centrado primordialmente na crítica à debilidade e hipocrisia de nossas sociedades, pensadas a partir dos ruídos provocados por suas diferentes relações de poder, Los detectives salvajes (1998) é justamente uma espécie de experimento anterior a este seu último trabalho, em que o autor articula a sua condição de detetive em favor da abordagem criativa e substancial da temática literária, enquanto instrumento de vida e morte. Ao rastrear as condições cotidianas em que se dá a produção e a veiculação da poesia moderna, vista não apenas enquanto gênero, mas antes de tudo, como fenômeno estético e humano, pensando, por exemplo, em um contexto situado nos primeiros anos da década de 1970, no México, que é, aliás, o ponto de partida para o desenrolar das sucessivas aventuras de García Madero, personagem primordial para o romance em destaque, e para a incursão dos episódios que compõem a narrativa, Bolaño insiste em não dissimular a febre e a loucura, que o sujeito contemporâneo tanto se esforça para esconder.

Em meio ao pranto e às gargalhadas, que representam os dois pólos de uma travessia por onde desfilam dramaticamente as experiências do autor, o seu olhar se ocupa de investigar as mazelas que constituem a condição humana, revelando-as como feridas 
abertas, sempre dispostas a nos espreitar, a nos inquirir, a sujar as nossas mãos de sangue, talvez o mesmo líquido vermelho e prurido que escorreu vertiginosamente do corpo de Cesárea Tinajero, a poeta desaparecida em seu universo ficcional, e que não nos permite esquecer a nossa barbárie, a nossa estranheza. Bolaño percebe a importância de não negar o protagonismo da tragédia e de compreender a sua natureza, no âmbito das sociedades contemporâneas, e como consequência disto, permite que o seu pensamento seja guiado pela agonia, de maneira que a sua narrativa seja tomada por determinado sentimento de horror e suas frequentes formas de configuração. A atividade do autor relaciona-se, portanto, com o espelhamento de sombras mortas, predominantes em um mundo literário que chama a atenção não apenas por sua qualidade imaginativa selvagem, mas também por sua conexão com o mundo real marcado, dentre outras coisas, pela disseminação da violência e seus diferentes meio de atuação.

O detetive da vida e dos versos a que nos referimos neste trabalho, à proporção que empreende o seu método de busca e vasculhamento da realidade, não da realidade factual, comprovadamente consumada, e sim das possíveis formas de configuração do real, conduz os seus personagens para um planeta absurdo, fazendo com que todos eles se percam por entre os caminhos estreitos em que transitam a loucura, o mal, o valor, o medo, a culpa e a melancolia. Embora sejamos seduzidos a acreditar que a atmosfera apresentada por Bolaño tenha um cunho enciclopédico e seja, de certo modo, estritamente real, temos clareza de que o seu mundo não se preocupa em estabelecer uma correspondência precisa com os referentes do real, ainda que em grande parte do romance isso possa transparecer, graças ao aparecimento de tipos humanos que além de circularem dentro da narrativa também transitam livremente em seu universo não-ficcional. No entanto, não podemos dizer que o mundo produzido por este detetive de lentes embaçadas habite o espaço da ciência-ficção ou da literatura policial, já que aos olhos da crítica especializada, dentro da qual se destaca o nome do estudioso Franklin Rodríguez (2015), é possível afirmar que:

En su obra, la continua combinación de lo objetivo con el subjetivo sirve para incrementar la complejidad de lo narrado, para darle la oportunidad al lector de presentir y buscar los distintos niveles de escritura, sabiendo que están presentes, pero que requieren esfuerzo. Sus personajes se aproximan con frecuencia a un mundo de sátira y poesía negra, de comedia que ilumina la tragedia, de homenajes y cortes de arma blanca, un mundo que combina eventos concretos y, se podría decir, de carácter social y político inconfundible, con escapes incómodos hacia lo indefinible, lo inconcluso y el mundo de los fragmentos. [...] Los diferentes mundos y sus personajes, desde Santa Teresa y Villaviciosa hasta Gerona y Kostekino, son sobre todo literatura, vida y muerte creadas con los referentes de la experiencia humana y con traumas históricos y sociales, literatura que pudo abrir los ojos en la oscuridad y bailar convincentemente con los espectros, que pudo habitar la pesadilla y los diferentes niveles de la aventura hacia lo desconocido, los diferentes niveles de realidad fuera de los parámetros que la limitan (RODRÍGUEZ, 2015, p.15-16). ${ }^{1}$

\footnotetext{
${ }^{1}$ Tradução nossa: Em sua obra, a contínua combinação do objetivo com o subjetivo serve para incrementar a complexidade daquilo que é narrado, para dar ao leitor a oportunidade de pressentir e buscar os distintos níveis de escritura, sabendo que eles existem e se fazem presentes, mas é preciso esforço para encontrá-los. Seus personagens se aproximam com freqüência ao mundo da sátira e da poesia negra, da comédia que
} 
Esta combinação entre o caráter objetivo e subjetivo, em nome da construção de um mundo igualmente povoado pela sátira e pela tragédia, o que, em certo sentido, determinam a escritura de Bolaño, nos faz enxergar a este escritor como um sujeito multifacetado, um detetive do nada e do absurdo, que embora tenha vivido apenas 50 anos, nos transmite a ideia de que viveu muitas vidas em uma só, e que se dedicou a observar tantas outras. Assim, é possível dizer que o mundo literário que aparece em Los detectives salvajes e que se comunica praticamente com toda a obra do autor, seja a narrativa, a poesia ou a crítica, no caso específico de Entre paréntesis (2004), se revela respaldado pela explanação de uma realidade imaginária (conflitante, vulgar, sombria e decadente), que é, aliás, o tônus revitalizante da própria literatura e também o componente fundamental de nossa condição. Trata-se de um mundo que pertence exclusivamente ao autor, repleto de calamidades que se apresentam indistintamente como planos paralelos, indispensáveis ao valor e à honradez mediante as quais é possível lutar por uma existência digna, sem se envergonhar, sem fugir do combate, sem entregar-se de joelhos clamando por trégua.

Assim, a mesma marginalidade e fatia de derrota ou fracasso que lhe impuseram uma vida, de certo modo, miserável, também lhe asseguraram a construção de um espaço em que pudesse desenvolver sua obra no início da vida literária, transformando aquilo que, em princípio, fora apenas um emaranhado de dificuldades e perturbações (imaginadas ou reais), em componentes estruturais de sua escrita. Rodeado pelo mito de si mesmo, o nosso investigador escolheu a literatura como forma de vida e se entregou vorazmente a esta aposta sem maiores expectativas, tal qual um mercador do deserto, que, sem saber guarda em sua estante a relíquia mais cobiçada. E o seu valor está justamente na perícia com a qual investiga a si mesmo e reconhece suas mazelas, seus dramas, sua dor; tudo isto substâncias para a afirmação de um mundo auto-referente, um mundo criador de suas próprias verdades e aventuras, revelando-se, assim, um hábil detetive capaz de decifrar todos os crimes cometidos em uma realidade produzida por alguém que assumiu a entrega total à literatura como seu único destino.

Neste caso, o pensamento de Bolaño, à medida que incorpora as batalhas que lhe são imputadas pela vida e pela atividade de escritor, à semelhança de sua literatura, passa a refletir sobre a ideia de valor, suscitada não apenas pelo imaginário de seus leitores diante das armadilhas interpretativas semeadas no romance, aqui em questão, também faz com que esse termo se destaque como eixo representativo de seu legado literário, no que diz respeito ao circuito de leitura e produtividade das literaturas em língua espanhola, na

ilumina a tragédia, de homenagens e cortes de arma branca, um mundo que combina eventos concretos, e até se pode dizer, de caráter social e político inconfundível, com fugas incômodas até o indefinido, o inconcluso e o mundo dos fragmentos. [...] Os diferentes mundos e seus personagens desde Santa Teresa e Villaviciosa até Girona e Kostekino, tratam antes de qualquer coisa sobre a literatura, vida e morte criadas com os referentes da experiência humana e com traumas históricos e sociais, literatura que é capaz de abrir os olhos na escuridão e bailar convincentemente com os espectros, que pode estar nos pesadelos e nos diferentes níveis de aventura até o desconhecido, os diferentes níveis de realidade fora dos parâmetros que a limitam (RODRÍGUEZ, 2015, p.15-16). 
Espanha e na América Latina, afirmando-se, desse modo, como senha de acesso à sua ficção.

Os detetives que habitam esta narrativa não absorvem a noção de valor enquanto um ideal romântico, como em princípio se poderia imaginar. Arturo, Ulises, García Madero e a própria Lupe que, em determinado momento abandona o ofício de prostituta, permitindo que sua rota seja completamente alterada (muito mais pelo exercício do acaso do que pelo arbítrio da personagem), passa a viver a mesma saga de seus companheiros, não perseguiam a virtude, nem para o bem nem para o mal. A ação deste grupo, como talvez a própria ação de Bolaño, era justificada pelo desejo, por vezes insano, de viver e escrever a partir de um espaço tensionado pelo valor e pelo medo, uma zona de conflitos onde se multiplicam suas reflexões, rastreando e combatendo, de alguma maneira, as nossas subalternidades.

Essa abordagem obsessiva das armadilhas que cercam a atividade do escritor e o tratamento obscuro e visceral que é concedido aos seus personagens, quase sempre carregado de uma dose exagerada de auto-fabulação, impõem a arquitetura de zonas de perigo, um verdadeiro campo minado, sempre disposto a explodir diante de qualquer movimento desatento, seja ele cometido pelo autor, por nós, leitores, ou ainda pelos diferentes tipos humanos que povoam a sua narrativa. Esta areia movediça sob a qual se escondem os nossos fantasmas, as nossas memórias, os ossos de nossos ancestrais, cadáveres em estado de putrefação, incita o movimento de nossos pés, que devem caminhar descalços e firmes, mas sempre em estado de alerta, conforme destaca Rodrigo Fresán (2008, p.295): "Bolaño escribía desde la última frontera y al borde del abismo. Solo así se entiende una prosa tan activa y cinética y, al mismo tiempo, tan observadora y reflexiva. Solo así se comprende su necesidad impostergable de ser persona y personaje.”2

Ao mencionar alguns nomes (em entrevistas, ensaios críticos ou mesmo em muitas páginas de sua farta obra), como por exemplo, Jorge Luis Borges, Enrique Lihn, Juan Rulfo, Sergio Gonzáles Rodríguez, Arthur Rimbaud, Franz Kafka, os irmãos Nicanor Parra e, em especial, o poeta mexicano Mario Santiago, por quem Bolaño nutria não apenas grande estima, como também considerava um dos maiores poetas que já havia tomado conhecimento, o investigador desvelado identifica a importância do valor e a sua escolha como companheiro de viagem. De tal maneira, o destaque dado a estes nomes, tenham sido eles ficcionalizados ou não, atrela-se significativamente à relação estabelecida entre a ideia de valor e a força do ato criativo, de forma que este primeiro, quando posto em tensão com a ideia de medo, passe a constituir o cenário onde se estabelecem os territórios da escritura de Bolaño.

É exatamente neste campo de ossos, o cemitério que também abriga os nossos fantasmas e os cadáveres de nossos ancestrais, onde a ficção do autor promove a reflexão a respeito do valor. Na contramão daquilo que afirmou Ernest Hemingway, quando em correspondência a Ezra Pound, disse-lhe que a arte e o valor somente poderiam se combinar exemplarmente, caso estivessem os dois, a um só tempo, em uma praça de

2 Tradução nossa: Bolaño escrevia desde a última fronteira e à beira do abismo. Somente assim se pode entender uma prosa tão ativa e cinética e, ao mesmo tempo, tão observadora e reflexiva. Somente assim é possível compreender a sua necessidade inadiável de ser pessoa e personagem (FRESÁN, 2008, p.295). 
touros (HEMINGWAY, 1941, p.57), Bolaño nos apresenta um projeto literário em que seus personagens reconhecem habilmente o movimento destes animais, podendo, assim, antever a direção do ataque. Aí reside o estreitamento entre a vida e a ficção, potencializando consequentemente o surgimento de uma zona intermediária, em certa medida fictícia e em certa medida real, em que o sonho, o devaneio e a transgressão são elementos fundamentais para a consolidação do valor como ponto de partida para a construção de cenários e intrigas, eixo temático em que a escrita se transforma na própria arena por onde desfilam os touros e os carros de boi, enquanto o toureiro, este detetive selvagem de vestes negras e capa vermelha, espreita o animal sorrateiramente, sob o patrocínio da dúvida e da virtude.

Parece-nos claro que as experiências desencadeadas pelos personagens que aparecem em Los detectives salvajes despontam sempre sublinhadas por circunstâncias que sinalizam a maneira particular com que estes sujeitos dialogam repetidas vezes com o valor. Assim, as travessias que são realizadas ganham um maior significado, quando são conectadas à experiência do medo e ao protagonismo do valor, ou quando são dispostas em formato curvilíneo, de modo a incitar a nossa reflexão sobre as estratégias de atuação dos personagens diante dos diferentes destinos lançados como um jogo de dados pela estrada.

Independentemente do caminho escolhido por estes andarilhos, é certo que os percalços encontrados durante suas trajetórias, assim como a ocorrência de determinados episódios, descritos na maioria dos casos em alucinante continuação, evocam diferentes variáveis do valor, percorrendo extremos que vão desde a valentia sobressaltada em face da iminência da morte, da desventura ou do desaparecimento, até o predomínio do medo e da temeridade, como fluxos contínuos deflagrados desta noção de coragem compreendida enquanto virtude.

Afinal, ainda que movidos pelo destemor, todos os toureiros são tomados pelo medo quando atravessam o túnel que os levará até à arena, e é justamente este sentimento o que move a ação destes homens durante o espetáculo. Em certa medida, o medo é o grande combustível para o desenvolvimento das relações do autor e de seus personagens com o valor, assim como para a tomada de possíveis reações diante dos infortúnios que lhe são ditados pela vida. E esse valor, promovido quase sempre pela viagem e pela ideia de deslocamento, converte-se na catarse, que, em fração de segundos, é capaz de fazer com que a temeridade e o medo, em princípio absolutamente deploráveis, motivem, por exemplo, o resgate de senhoras indefesas, vítimas de um incêndio qualquer. Para isso, no entanto, é imprescindível que cada indivíduo compreenda a necessidade de que se desloque por diferentes planos, ora como o detetive selvagem que rastreia incessantemente as pistas de sua existência, ora enxergando-se como peça de um quebracabeça gigante que perde a sua razão de ser caso se mantenha fixado no mesmo vazio, já que para Bolaño:

En un principio, para mí el viaje era esencial. El viaje, en el imaginario de mi generación, era el viaje de los beatniks. Y eso se prolongo varios años después, incluso cuando viajé por Europa. Pero hay un momento en que todo viene a ser lo mismo. El paisaje varía, la arquitectura varía, pero la mecánica del viaje, las revelaciones del viaje, se empiezan a repetir. 


\begin{abstract}
El viaje, cuando eres joven, es una especie de epifanía de grandes apariciones. ¿Y qué es lo que aparece? Apareces tú mismo, pero en vez de aparecer solo [...] de pronto apareces rodeado, y todo eso lo proyectas en tu gran escenografía de viaje. O bien en tus deseos, o bien en la colisión entre tu deseo y ese paisaje cambiante. Y eso para la poesía es magnífico. Tanto como el sexo, que en los viajes es siempre genial, pues es un sexo promiscuo, siempre dispuesto. En fin, con cosas que en la juventud son anfetamínicas. Pero hay un momento en que eso se agota. Evidentemente, Mauritania no es igual que Alemania, pero hay historias en ambos países que se repiten (BRAITHWAITE, 2006, p.57). ${ }^{3}$
\end{abstract}

Atrelada, portanto, às histórias de alguns personagens marcados pela resistência e a este ideal de valor, seja como temeridade ou virtude, a viagem desempenha um papel relevante na construção desta narrativa, uma vez que intermedeia o desenvolvimento de experiências por onde transitam silenciosos os passos do próprio Bolaño, revelando, pois, o movimento como parte fundamental do processo de busca e criação. Estamos mesmo diante de um poeta-detetive que tem sua imagem refratada no objeto de sua investigação, neste caso Cesárea Tinajero. As figuras dos jovens poetas, herdeiros do real visceralismo, entrecortadas e esmaecidas pelo lapso temporal de vinte anos, já que empreendem sua busca desde 1976 e seguem se movimentando em função dela até 1996, convergem para um deserto de ossos, possivelmente a região de Sonora, dando ênfase à múltipla concepção de valor sugerida pelo romance.

Todavia, convém ressaltar que não estamos tratando de destacar alguma essência de caráter no comportamento destes personagens, enxergando-os mediante uma ótica romântica ou heroicizante, mesmo que estes traços, de alguma maneira, apareçam desordenadamente em determinados momentos da narrativa, mas sim de entendê-los em meio às lutas cotidianas, às adversidades, ao medo e à proximidade do abismo que lhes exigem destemor e uma entrega radical. A luta contra o advento do medo é, na verdade, uma manobra, muitas vezes arriscada, já que submete estes sujeitos a uma condição de risco iminente que pode lhes custar a própria vida. No entanto, quando assumem a errância como bandeira de luta e sobrevivência, os poetas-detetives deste romance são capazes de intuir que suas aventuras os levarão exaustivamente até os limites desta experiência de busca e auto-reconhecimento.

$\mathrm{Na}$ arena, diante dos touros, se pensarmos na alegoria de Ernest Hemingway, estes sujeitos não podem recuar, a única forma de resistir, e talvez sobreviver, é lançando-se

\footnotetext{
${ }^{3}$ Tradução nossa: Houve momentos que para mim a viagem era essencial. A viagem, no imaginário d minha geração, era a viagem dos beatniks. E se estendeu por vários anos depois, inclusive quando viagem pela Europa. Mas existem momentos em que tudo vem a ser o mesmo. A paisagem varia, a arquitetura varia, mas a mecânica da viagem, as revelações da viagem começam a se repetir. A viagem, quando somos jovens, é uma espécie de epifania de grandes aparições. E o que aparece por detrás das sombras? Aparecemos nós mesmos, mas ao invés de aparecermos sozinhos [...] imediatamente surgimos no meio de uma multidão, e tudo isso é projetado a partir da escenografia da viagem. Seja em nossos desejos, seja na combinação de nossos desejos com essa paisagem cambiante. E isso para a poesia é magnífico. O mesmo acontece com o sexo, que durante as viagens é sempre genial, pois é um sexo promíscuo, sempre disposto. Enfim, são coisas que na juventude alucinantes. Mas há um momento em que tudo isso nos cansa. Evidentemente, a Mauritânia não é igual à Alemanha, mas existem histórias nos dois países que se repetem (BRAITHWAITE, 2006, p.57).
} 
contra as feras, assumindo o risco de que não voltem e de que, em meio à cortina de poeira que cega às vítimas e aos algozes (ainda que estas posições se invertam inadvertidamente, a fim de assegurar a beleza do espetáculo), seus corpos tombem sobre o solo revolto. O regresso triunfante é apenas uma esperança, um farol vermelho acenando ao longe, tal qual se pode notar na última cena da primeira parte do livro (1. Mexicanos perdidos en México - 1975), que introduz uma fuga alucinante realizada pelos amigos Ulises Lima, Arturo Belano, Lupe e, por fim, García Madero:

Hasta las diez de la noche era posible ver, al otro lado de la verja, las siluetas de Alberto y sus pistoleros. A las once ya no estaban. [...] A las doce y cuarto, todos nos trasladamos sigilosamente al garaje y empezaron las despedidas. Abracé a Belano y a Lima y les pregunté que iba a pasar con el real visceralismo. No me contestaron. Abracé a Lupe y le dije que tuviera cuidado. En respuesta recibí un beso en la mejilla. El coche de Quim era un Ford Impala último modelo, de color Blanco, y Quin y su mujer quisieron saber, como si en último minuto se hubieran arrepentido, quien iba a ser el conductor.

-Yo -dijo Ulises Lima.

[...] El motor del coche ya estaba encendido y todos parecían estatuas de sal. Vi a Arturo y a Lima en los asientos delanteros y a Lupe en el asiento posterior.

-Alguien tiene que ir a abrir la puerta de la calle - dijo Quim. Me ofrecí a hacerlo.

Estaba en la acera cuando vi encenderse las luces del Camaro y las luces del Impala. Parecía una película de ciencia ficción. Mientras un coche salía de la casa, el otro ce acercó, como atraídos por un imán o por la fatalidad, que viene a ser lo mismo según los griegos.

Escuché voces, me llamaban, a mi lado pasó el coche de Quim, vi la silueta de Alberto que bajaba del Camaro y de un salto estaba junto al coche en donde iban mis amigos. Sus acompañantes, sin bajarse, le gritaban que rompiera una de las ventanas del Impala. ¿Por qué no acelera?, pensé. El padrote de Lupe empezó a patear las puertas (BOLAÑO, 1998, p.135136). ${ }^{4}$

\footnotetext{
${ }^{4}$ Tradução nossa: Até as dez da noite ainda era possível ver, do outro lado da cerca, a silhueta de Alberto e seus capangas. As onze já não estavam. As doze e quinze, todos caminhamos silenciosamente até a garagem e começamos a nos despedir. Abracei a Belano e a Lima e lhes perguntei o que iria acontecer com o real visceralismo. Não me disseram nada. Abracei a Lupe e lhe recomendei que tivesse cuidado. Em resposta recebi um beijo na bochecha. O carro de Quim era um Ford Opala branco de último modelo, e Quim e sua mulher perguntaram, como se no último instante tivessem se arrependido de emprestar o veículo, quem seria o motorista.

-Eu -disse Ulises Lima.

[...] O motor do carro estava ligado e todos pareciam estátuas de sal.

Vi Arturo e Ulises nos bancos dianteiros, e Lupe estava sentada no banco traseiro.

- Alguém tem que ir abrir o portão da rua - disse Quim.

Me dispus a fazer isso.

Eu estava na calçada quando percebi que os faróis do Camaro estavam acesos e os do Opala também. Parecia um filme de ficção científica. Enquanto um carro saia de casa, o outro se aproximou, como se estivessem sendo atraídos por um imã ou por alguma fatalidade, o que vem a ser a mesma coisa segundo os gregos.
} 
Situado na noite de réveillon de 1975, o fragmento, em destaque, descreve os preparativos para a fuga dos poetas real visceralistas, que, sob o pretexto de salvaguardarem a prostituta Lupe dos desígnios de seu cafetão Alberto, se dispõem a empreender uma viagem desesperada pelo acaso e pela margem. Embora estejam certos da necessidade de que se desloquem daquele espaço - objetivamente tratava-se da residência das irmãs María e Angélica Font, também seguidoras da poesia visceral. Em verdade, estes indivíduos não sabem, ao certo, do que estão fugindo, nem tão pouco o que desejam alcançar. Sabem apenas que precisam mover-se pelas estradas do México, à procura dos rastros da poeta Cesárea Tinajero, mas também assumir uma postura combativa ante à vida, reafirmando o diálogo estabelecido com a ideia de valor, e não aquele plantado pelas ideologias dominantes, mas um outro, produzido, inclusive, pela "covardia" e pelo "desvalor", se pensados como motores para a realização de determinados atos de rebeldia.

A dualidade vivida pelos personagens de Bolaño e também partilhada pelo autor se destaca, neste momento, como peça fundamental para o entendimento contraditório desta noção de valor. Nas reflexões propostas em sua obra Ética a Nicômoco (1991), Aristóteles apresenta uma definição para este termo, cunhada, em um plano estritamente paradoxal. Conforme as considerações do pensador, o valor é, em certo sentido, uma virtude moral que, à semelhança do que acontece com algumas outras, está situada em uma posição intermediária entre os sentimentos menos desejados, a temeridade e o medo. Assim, um ato de valor ou um indivíduo dito valente, são definidos nestas circunstâncias, de maneira que o reconhecimento de uma ameaça demande, num primeiro instante, o aparecimento do medo, mas posteriormente, este sentimento acaba se convertendo em confiança e enfrentamento.

É certo que a aproximação destacada entre o valor e o medo solicita que a temeridade seja acolhida para que a partir dela possam vir à tona os elementos que se coordenam para a realização de um ato valente. No entanto, isso não significa que o medo seja completamente erradicado; ele estará sempre ali, e é justamente a partir de sua existência e do contato mantido com os seus variantes que o valor do escritor e dos poetas-detetives será afirmado, tal qual se pode notar no fragmento seguinte (uma sequência da cena anteriormente destacada), em que García Madero, numa espécie de ímpeto valoroso, adentra a Opala de Quim Font, juntando-se espiritualmente aos seus amigos:

[...] Vi el rostro de Ulises y sus manos que se movían por el tablero de mandos del coche de Quim. Vi la cara de Belano que miraba impasible al padrote, como si la cosa no fuera con él. Vi a Lupe que se tapaba la cara en el asiento trasero. Pensé que el vidrio de la puerta no iba

Escutei vozes que chamavam por mim, do meu lado passou o carro de Quim, vi a sombra de Alberto que descia do Camaro e de repente se aproximou do outro carro onde estavam meus amigos. Seus companheiros, sem descer, lhe diziam que quebrasse o vidro de uma das janelas do Opala. Por que não acelerava?, pensei. O cafetão de Lupe começou então e dar chutes nas portas (BOLAÑO, 1998, p.135-136). 
a resistir otra patada y de un salto me vi junto a Alberto. [...] Vi mi puño derecho (el único libre pues en la otra mano llevaba mis libros) que se proyectaba otra vez sobre el cuerpo del padrote e en esta ocasión lo vi caer. Sentí que me llamaban de la casa y no me volví. Pateé el cuerpo que estaba a mis pies y vi el Impala que por fin se movía. Vi salir a los dos matones del Camaro y los vi dirigir hacia mí. Vi que Lupe me miraba desde el interior del coche y que abría la puerta. Supe que siempre había querido marcharme. Entré y antes de que pudiera cerrar Ulises aceleró de golpe. Oí un disparo o algo que parecía un disparo. Nos han disparado, hijos de la chingada, dijo Lupe. Me volví y a través de la ventana trasera vi una sombra en medio de la calle. En esa sombra, enmarcada por la ventana estrictamente rectangular del Impala, se concentraba toda la tristeza del mundo. Son fuegos artificiales, oí que decía Belano mientras nuestro coche daba un salto y dejaba atrás la casa de las hermanas Font, el Camaro de los matones, la calle Colima y en menos de dos segundos ya estábamos en la avenida Oaxaca y nos perdíamos en dirección al norte del DF (BOLAÑO, 1998, p.136137)..$^{5}$

Movida pela ação descontínua de seus atores e pelo dinamismo com que os eventos se processam, ou ainda pelo medo circunstancial de García Madero e a sua reação sobressaltada (sem qualquer planejamento) diante da ameaça representada por Alberto, a fuga desesperada destes jovens poetas inspirada pela voluptuosidade de Lupe representa, em um primeiro instante, o corte do fluxo narrativo desenvolvido na primeira parte do romance, já que a partir dali o personagem empresta a sua voz a incontáveis sujeitos que passam "a contar a história", aparecendo e desaparecendo como flashs, todos eles a serviço da memória e do arbítrio do autor.

Neste caso, além de apontar a abertura de um segundo plano ficcional, em que os tempos e os espaços se movimentam livremente (passado, presente e futuro se invertem sem aviso prévio), esta fuga acena também para uma reflexão acerca da história latinoamericana, tomando o México como marco referencial, construída através da violência e da barbárie. Ao cruzar a janela que lhe separava de seu algoz, os olhos de García Madero avistaram toda a tristeza do mundo, e se na área exterior ao Opala habitavam a sombra, o medo e a melancolia, dentro do veículo seguiam intrépidos o valor, a coragem, a honradez do toureiro diante dos chifres afiados do touro, e, quem sabe, até mesmo a esperança.

\footnotetext{
${ }^{5}$ Tradução nossa: [...] Vi o rosto de Ulises e suas mãos que se moviam pelo painel do carro de Quim. Vi a cara de Belano olhando impacientemente para o cafetão, como se ele não tivesse nada a ver com tudo aquilo. Vi Lupe cobrindo o rosto com as mãos no banco de trás. Pensei que o vidroo da porta não fosse resistir a outro chute e de repente me vi junto a Alberto. [...] Vi meu punho direito (o único livre já que na outra mão eu carregava meus livros) que se projetava de novo contra o corpo de Alberto e nesse instante o vi cair. Senti que me chamavam da casa e não me virei. Pisei sobre o corpo que estava diante de meus pés e vi a Opala por fim se mover. Vi dois capangas descerem do Camaro e caminharem em minha direção. Vi que Lupe me olhava de dentro do carro e que abriu a porta. Eu sempre soube que desejava fugir. Entrei e antes que pudesse fechar a porta Ulises acelerou de uma só vez. Ouvi um disparo ou algum barulho que se parecia a um disparo. Atiraram em nossa direção, filhos da puta, disse Lupe. Virei e pela janela do fundo vi uma sombra no meio da rua. Nessa sombra, emoldurada pela janela estritamente retangular da Opala, se concentrava toda a tristeza do mundo. São fogos de artifício, escutei o que dizia Belano enquanto nosso carro arrancava cada vez mais e deixada para trás a casa das irmãs Font, o Camaro, os capangas, a rua Colima e em menos de dois segundos já estávamos na avenida Oxaca e nos perdíamos em direção ao norte do DF (BOLAÑO, 1998, p.136-137).
} 
Fugir, nesse sentido, levando-se em conta o nítido interesse de Bolaño em problematizar a temática do valor, significa penetrar em uma linhagem literária que entende a escritura como campo minado, de modo que a tensão estabelecida entre a ansiedade e a autoconfiança diante do medo se resolva sem que autor ou personagens tenham a intenção de encontrar uma solução heróica para esta problemática. De tal maneira, considerando as discussões levantadas por Walter Benjamin, no seu estudo intitulado Dois poemas de Friedrich Hölderlin: "Coragem de poeta" (Dichtermut) e "Timidez" (Blödigkeit), publicado em 2013 pela Teresa Revista de Literatura Brasileira, é possível mencionar que o paradoxo a que nos referimos também revela uma relação de mútua dependência entre a virtude e o medo, mas que na concepção do teórico acaba assumindo outro caminho:

O objeto de Hölderlin na primeira versão de seu poema é um destino: a morte do poeta. Ele canta as fontes da coragem para tal morte. Esta morte é o centro a partir do qual deveria surgir o mundo da morte poética. A existência naquele mundo seria a coragem do poeta. A voz se ergue timidamente apenas para cantar um cosmos para o qual a morte do poeta significa o próprio declínio. [...] Estranhamente, a coragem do poeta se fundamenta ainda em outra ordem, alheia. A do parentesco dos viventes. Deste parentesco ele ganha ligação com seu destino. Que pode significar para a coragem poética o parentesco com o povo? Não se torna sensível no poema o direito mais profundo que permite ao poeta apoiar-se em seu povo, nos viventes, e se sentir aparentado a eles. Sabemos ser esta ideia uma das mais consoladoras para os poetas, sabemos que era especialmente cara a Hölderlin. Contudo, a ligação natural com todo o povo não pode ser justificada para nós como condição para uma vida poética. Por que o poeta não celebra - com maior razão - o odi profanum? [...] Da maneira mais surpreendente o poeta se agarra com ambas as mãos a ordens de mundo alheias, ao povo e ao deus, a fim de edificar em si sua própria coragem, a coragem dos poetas. Mas o canto, o interior do poeta, a fonte significativa de sua virtude, parece, ali onde ela é nomeada, frágil, sem força nem grandeza (BENJAMIN, 2013, p.588).

A partir da leitura de Benjamin dos textos de Hölderlin, entendemos que o crítico não alimenta a tensão existente entre a coragem e o temor, assinalando, pois, um terceiro caminho marcado pela mobilização de elementos discursivos capazes de eventualmente resolverem este embate. Diante disso, a sua análise nos apresenta uma solução transcendental (mesmo que cunhada no campo das contradições), pautada em níveis avançados de complexidade dado ao caráter subjetivo com o qual esta questão é pensada, a fim de que o sujeito dotado de valor, neste caso o poeta, consiga amalgamar pacificamente o valor e o medo. O resultado dessa fusão resultaria no reconhecimento de uma suposta unidade exteriorizada pelas relações entre os sujeitos, de maneira que os olhares lançados para a morte, a virtude e o etéreo pudessem convergir para um mesmo pólo, constituindo uma diretriz universal em que estas contradições se aportem e se resolvam.

De outro lado, no entanto, a leitura de Benjamin se coloca como ponto de partida para a validação deste paradoxo (temeridade $\mathrm{X}$ virtude) e para a sua tomada enquanto combustível, possivelmente insubstituível, no que diz respeito à composição da escrita literária, desde os clássicos, passando por Kafka até que cheguemos a Bolaño. E no caso deste último, sabemos que a desventura conjugada ao medo e ao valor resultou na 
afirmação de um espírito rebelde totalmente entregue ao combate, à tragédia, à violência e à aventura. A coragem e suas contradições, assim como a produção de uma narrativa visceral, convergem para a realização de uma experiência de vida que, aqui, se confunde com a própria experiência literária caracterizada pela abordagem intensa, dramática, e ao mesmo tempo irônica, de diferentes temas, ao passo que o protagonismo do valor comprometa o rumo que é dado a cada um dos personagens, auferindo, assim, ao romance uma indiscutível consistência e profundidade.

\section{REFERÊNCIAS}

ARISTÓTELES. Ética a Nicômaco. In: Poética. Seleção de textos de José Américo Motta Pessanha. 4. ed. São Paulo: Nova Cultural, 1991.

BENJAMIN, Walter. Dois poemas de Friedrich Hölderlin: "Coragem de poeta" (Dichtermut), "Timidez" (Blödigkeit). Trad. de Mário Luiz Frungillo. Teresa Revista de Literatura Brasileira. São Paulo, vol.12, n. 13, p. 584-603, 2013.

BOLAÑO, Roberto. 2666. Barcelona: Editorial Anagrama, 2004.

2004.

. Entre paréntesis: ensayos, artículos y discursos (1998-2003). Barcelona: Anagrama,

. Los detectives salvajes. Barcelona: Editorial Anagrama, 1998.

BRAITHWAITE, Andrés. Bolaño por si mismo: entrevistas escogidas. Santiago-Chile: Ediciones Universidad Diego Portales, 2006.

FRESÁN, Rodrigo. El samurái romántico. Bolaño salvaje. Editores. Edmundo Paz Soldán e Gustavo Faverón Patriau. Barcelona: Candaya, 2008.

HEMINGWAY, Ernest. Por quem os sinos dobram. 1 ed. Trad. Monteiro Lobato. São Paulo/Rio de Janeiro: Companhia Editorial Nacional, 1941.

MASSI, Fernanda. O romance do século XXI: manutenção, transgressão e inovação do gênero. São Paulo: Cultura Acadêmica, 2011.

RODRÍGUEZ, Franklin. Roberto Bolaño: el investigador desvelado. Madrid: Editorial Verbum, 2015.

Recebido em: 30/03/2017

Aprovado em: 28/05/2017

Publicado em: 01/06/2017 